\title{
Robots, Industry 4.0 and Humans, or Why Assembly Work Is More than Routine Work
}

\author{
Sabine Pfeiffer \\ Department of Sociology (550D), University of Hohenheim, Wollgrasweg 23, 70599 Stuttgart, Germany; \\ soziologie@uni-hohenheim.de; Tel.: +49-711-459-22622
}

Academic Editors: António B. Moniz and Bettina-Johanna Krings

Received: 25 February 2016; Accepted: 25 April 2016; Published: 3 May 2016

\begin{abstract}
This article condenses the key findings of qualitative studies on assembly work. Grounded conceptually in considerations of the role of experiential knowledge and living labor capacity with regard to informal expertise and tacit knowledge, the empirical results challenge the dominant view of assembly work as routine tasks that could easily be replaced by robotics. The empirical basis comprised of 62 qualitative interviews in five assembly plants provides answers to two questions: Are there non-routine aspects to be found in assembly work today? What exactly is the nature of experience in assembly work? The detailed research results are presented in three steps: the first focuses on the role of the non-routine in core assembly tasks; the second discusses the important and increasing role played by interactive capabilities in assembly work to ensure high performance, quality, and a smooth material flow; and the third highlights the usually neglected role of assembly workers in processes of innovation and organizational learning. The concluding chapter discusses the findings from the perspective of new technological options in robotics, possible worker resistance and effects on employment.
\end{abstract}

Keywords: assembly work; laboring capacity; tacit knowledge; automatization; Industry 4.0; robotics

\section{Robots on the Rise: The End of Human Assembly?}

One major topic of the 2016 World Economic Forum (WEF) was the so-called fourth industrial revolution. Advanced robots, which the WEF sees as one of the main technological drivers of said revolution, now equipped "with enhanced senses, dexterity, and intelligence", are not only acknowledged as "more practical than human labor in manufacturing" but also as appearing "in a growing number of service jobs"[1] (p. 7). Despite the particularly questionable database used to derive such detailed forecasts (online questionnaires returned by only 371 chief human resource officers of the 2450 biggest employers worldwide), robotics and autonomous transportation - unfortunately grouped into a single category-are predicted to create a worldwide job growth of $1.36 \%$ [1] (p. 11).

Although they have been around for some time in industrial production and assembly, robots have for decades had less attention than they receive nowadays, and they are expected to spread to other and less manufactural realms in the near future. The current debate on robotics takes up artificial intelligent approaches in robotics [2], war robots [3], and even smart algorithms, for example in journalism [4]. The term robot is increasingly used as a synonym for software robots as well, and too often apples and pears are mixed, so to speak, for example when Bessen compares bank machines (ATMs) in finance with robotics [5]. However, even a glance at the good old industrial robot finds the International Federation of Robotics (IFR) looking forward to a shining future: Not only does the world market show "another all-time high sales record with a growth rate of 15 percent" in 2014, similar growth rates are expected up to 2017, and still "the best is yet to come in the next decades" [6] (p. 3).

The new rise of robotics on one hand will doubtless provide bright prospects for the robot building sector and its companies, but on the other hand it begs the inescapable question regarding the future of 
those jobs still remaining today in industrial production. Assembly work in particular, which even in mass production often is still characterized by human work and hybrid or mere manual tasks, seems to be under pressure from technologically new and less expensive robotic approaches. As Nye [7] (p. 242) shows in his impressive comparative historical review of the 100-year industrial history, the assembly line today "in a new form is more productive than ever," thanks to robotics.

In order to explore the question of relations between today's assembly work, new technological options in robotics, and possible future effects on employment, the automotive sector is, as ever, the first place to start. This is due to the reason that we still see the largest part-assembly work in this sector, but also because of the impressive figures regarding robot sales. In 2013, 43,300 industrial robot units were sold in Europe alone; the growth in sales of 5\% since 2012 was significantly driven by car manufacturers increasing their robot installations by 17\% [6] (pp. 11-12). Although robots for assembly experienced a sales decline not seen for years, measured by applications worldwide, assembly still is ranked third after handling and welding robots; in 2013,50\% — half of all assembly robots-were sold in Japan (4629) and China (3313). In Germany- "by far the largest robot market in Europe" (p. 13) - the number was 853, adding to a worldwide stock of operational robots in assembly amounting to 132,184 in 2013 [6] (pp. 70-76).

The recent and widely acknowledged study of Frey and Osborne [8] sees assembly on the top of susceptible tasks, based on the assumptions that assembly work is strongly routinized and that routine is what is most easily replaced. The authors follow the conventional routine/non-routine distinction that is characteristic of virtually all approaches in labor market research from the last decades. From this perspective, assembly in particular, with its still-high proportion of manual tasks, is regarded as a prime example of routine work (for a critical perspective on this dominant theoretical approach see Pfeiffer/Suphan [9]).

Labor market research should not necessarily be criticized for categorizing assembly as routine and therefore as technologically replaceable. Because this discipline does not aim to research inside production plants with a qualitative view on the everyday realities of work life, researchers have to rely on other studies that investigate more particularly the nature of assembly. However, although assembly is still one of the major forms of industrial production, there has been little research into that kind of work at the level of tasks. The impressive study of Walker and Guest on the "man on the Assembly Line", first published in 1952, still waits for a worthy successor [10].

If experience is referred to at all in recent research on assembly work, the suggestion is that it is not all that necessary. For example, Levitt et al. [11], based on an amazing dataset from automotive production, on one hand do show how learning by doing accelerates productivity and that quality benefits in ramp-up phases on assembly lines. Although this is and has to be based on and driven by deeply human capabilities, the authors observe that the same learning curve is not necessary when the second shift takes over. They present figures that seem to bear this out, and they interpret the shorter learning curve in the second shift with the fact that the human experience that improved the ramp-up is then quickly transferred into objective knowledge " $(.$.$) embodied in the organizational capital of$ the plant" [11] (p. 4). However, they never ask or observe how this happens and who makes it possible. Additionally, they never scrutinize what kind of learned experiences are embodied or how they are codified, or whether another form of transfer might have occurred instead: the transfer of experience from one worker to the other or one shift team to the following. The research results presented in the following chapters try to unveil what most studies simply overlook: whether experience and, therefore, non-routine work plays a role in assembly. Furthermore, what is even more important, why and for what dimensions of informal knowledge and implicit capabilities may experience be of greater significance than is usually assumed.

One striking example I observed was in the car body construction area of one of the big automotive OEM (Original Equipment Manufacturers) in Germany, where in 2015 the head count of workers and the count of industrial robots reached the ratio of 1:1. On this specific shop floor, from 2001 to 2014 , a decline of the human workforce of $32 \%$ matched an increase of automation by $25 \%$. 
Due to strong unions and vital industrial relations characteristic not only of the German automotive sector but particularly for that specific production site, no job losses resulted from this development. Using qualitative research methods to look beyond the mere figures and explore more deeply the production processes of this highly developed, state of the art automated car body assembly plant reveals the inherent limits of the division of labor between robots and humans and the limits of robotic automatization.

Even here, where human work seems increasingly susceptible to automation and, indeed, an obsolete residuum on the verge of extinction, and where highly automated mass production is perfected to unseen productivity and robustness, human experience may be even more essential than ever-although this is mostly overlooked and neglected. On first glance the production seem to be flawless and smooth: technical processes living their own life along a continuous flow of parts, events and handling, and industrial robots following a perfectly choreographed dance. The still impressive number of humans left in this environment of steel, data, and cycle times again initially is mostly assumed to be left to two polarized task groups: highly qualified engineers and management that plan and oversee the entire process on one hand, and humans fulfilling simple tasks requiring only minimal qualifications, if any, such as inserting or removing parts, or being responsible for minor canter in intralogistics, or cleaning.

The reality, however, is very different: $90 \%$ of the workers in this car body production plant have at least a three-year vocational training. This qualification is necessary because they do a qualified job. During a normal and otherwise smooth shift, a worker responsible for the ballet of eight welding and handling robots intervenes 20 to 30 times per shift-not because of technical incidents but in order to prevent them. Although human work declined quantitatively over the years, its qualitative role increased with automation. With a plant availability of already around $90 \%$, every bit of additional automatization increases complexity and creates an even more vulnerable overall system where the smallest and seemingly insignificant single event can affect the whole on a big scale. To prevent major flaws in quality and productivity and to maintain an undisturbed overall process, the just-mentioned 20 to 30 human interventions per shift are indispensable. To do this, workers need formal qualification and experience, using implicit knowledge and experiential capabilities. Put in other words: what workers need to do is anything but mere routine work. Because new lightweight, adaptive, and smarter robots are set to conquer not only welding and handling but, more than ever, the realm of manual or semi-automated (hybrid) assembly, this article aims to analyze exactly what constitutes non-routine work.

This may, at first glance, be surprising, since non-routine immediately suggests the idea of highly qualified digital work in software development or in innovative fields such as collaborative engineering, or of interactive work in the care sector or in consulting. However, industrial assembly-the world of fitting, manipulating, and adjusting-overwhelmingly rates as routine work in today's discourse, and therefore is highly susceptible to replacement by robotic technology or other digital technologies currently discussed. As we saw, non-routine aspects of human work play an indispensable role even in the highly automated environment of mass car body production. Thus, this article assumes that such aspects will also be of importance in assembly work, perhaps even more so.

It is not immediately obvious that non-routine work, of all things, should receive focus in the field of industrial assembly work. However, this is precisely what this article attempts: not simply to assume that assembly is "low-skilled" work only combining routine tasks, but instead to investigate assembly work exploratively in all its dimensions in order to allow non-routine capabilities, if there are any, to reveal themselves. The analysis here shows that the supposed simplicity and routine character of assembly work is not all that simple and, furthermore, that assembly work is also packed with different aspects of non-routine tasks and the capabilities to cope with them.

The article presents in a condensed form the key findings of qualitative studies on assembly work. Accordingly, Chapter 2 gives a rough outline of the analytical concept: experiential knowledge and living labor capacity as a specific view on informal expertise and "tacit knowledge." This perspective 
brings into focus aspects such as feel for material, intuition, a flair for plant and equipment and the like. The results presented challenge the dominant view of assembly work as routine tasks that therefore could easily be given to robots and ask: Is there any non-routine to be found in assembly work today? What exactly is the nature of experience in assembly work? How does it find expression? The empirical basis for this study is a total of 62 qualitative interviews in five assembly companies. Chapter 3 gives an overview of the methodological research design and the sampling strategies.

The next step-the major part of this article-presents detailed findings from the empirical analysis, starting with an overall view and condensed presentation of the key results (Chapter 4). The more detailed research results are presented in three parts: Chapter 5 covers the role of non-routine tasks in assembly, startup, and malfunction, concentrating on the core tasks of assembly such as handling the material, comprising parts, products, equipment, and machinery. Chapter 6 reveals interactive capabilities that play an increasing role in assembly work but are mostly ignored in the conventional distinction of routine/non-routine tasks: It will be demonstrated how much interactivity is needed not only within the working group, but also to ensure high performance and quality and even a s mooth material flow despite observed flaws of the assembly-related ICT (information and communication technology) systems. Chapter 7 describes the usually neglected role of assembly workers in processes of innovation and organizational learning. The concluding Chapter 8 discusses the findings again from the perspective of new technological options in robotics and possible employment effects.

\section{A Theoretical Framework for Non-Routine: Subjectifying Work Action and Laboring Capacity}

Frey and Osborne [8] consider assembly and machine work to be highly susceptible to automation by robots, following suit to a standard way of thinking about the effects of technical change on labor markets: 10 years earlier, Autor, Levy and Murnane [12] classified work activity into non-routine tasks (analytical or interactive) and routine tasks (cognitive or manual), showing two effects of digitalization, a substitution effect (routine work is substituted) and a complementarity effect (support of creativity, flexibility and complex communication and thus of non-routine tasks). Our interest lies primarily on differentiating between "routine" and "non-routine". All the task-based studies take these categories to be central for estimating the technical potential of replacing human labor. Although they conceptualize "routine" as the most decisive category for assessing the effects of technical change in terms of the extent to which tasks can be automated, they contain only rudimentary attempts to define it. In the end, all task-based approaches equate routine with repetitive, monotonous work, and their elaborations, when any are offered, vacillate between denoting it as a quality of the activity itself or as an assumption about the extent to which the activity can be automated [13] (p. 37). Fernández-Macías/Hurley [13] also note that the widely accepted classifications of routine work "are not good measures of routine" because they ultimately derive from antiquated notions of production work and thus the "routine content of some jobs may be overestimated or underestimated when relying on these two variable categories" and that the extent of routine in different jobs "is not the key driver behind polarization-if anything, it is more related to upgrading, in a similar way as the cognitive index" (pp. 48 and 69).

When workplaces and technology are designed, experience-based abilities seldom play a role. However, everyone knows who the experienced co-workers, the "old hands," are. The special understanding these experienced workers have, knowing as they do the name of the game, is the edge they have over the rookies in their workplace-these are all factors that are seldom visible from the outside. This also stems from the fact that experience is personal and always comprises informal, implicit, individually distinct knowledge and action. These qualities are difficult to pin down; they cannot be loaded into databases or conveyed as theoretical knowledge. The importance of experience is noticed, for the most part, when it is lacking: when the work station has already been moved or the co-worker has retired. Research approaches to these kinds of "tacit skills" often root in Polanyi [14], or Dreyfus [15], and derive from ethnographic and qualitative methods: Kusterer ethnographically describes how routine assembly line work fails to eliminate worker insight and 
involvement [16]; Zuboff [17], drawing on in-depth interviews with workers and managers in various industries, explores the historical role of the body as a primary source of know-how, and the challenges to human knowledge by computer-mediated work. Suchman [18] considers embodiment, emotion, and sociality necessary for humanness (p. 229) and draws attention to the ways in which even plans of action open out onto a sphere of embodied action and lived experience (p. 21). With respect to project rather than line work, Strauss [19] stresses how the totality of work requires a "supra-type of work" he calls articulation work, defined as work "that is involved in organizing both the tasks and relationships to them of the people who perform them" (p. 4). Consistent with these conceptual traditions, we introduce two theoretical frameworks from the German sociology of work literature we used for our empirical study. In this article we focus on the nexus of knowledge, work, and experience as clearly captured in the phrase "experience-based knowledge work." Knowledge, work, and experience-these are three concepts not necessarily normally linked. In order to think about them and study them as one, we had recourse in the project to use two concepts from industrial and labor sociology: the concept of subjectifying work action [20] and, connected with it, laboring capacity [21].

In German industrial sociology, since the 1980s, the concept of subjectifying work action has been trying to define categories that describe and empirically study these overseen qualities of human labor, qualities of experiential, tacit and informal skills that are so difficult to define. One of the first studies conducted on the basis of said concept revealed that skills and qualifications based on empirical knowledge and individual capabilities, such as a feeling for machines and materials, continue to play an important part in a digitized work environment, empirically shown first by work with computer-controlled machines [22]. Skills of this kind have been receiving neither practical nor systematic consideration and are regarded as tacit skills in most cases. The negation reaches further and hints to one important dilemma: "Although the criteria identified with the model of skilled work stress responsibility, individual initiative and creativity, they largely eliminate subjective factors such as emotions, sensations or impressions derived from personal experience. These may have significance for individual motivation and subjective satisfaction, but for the "correct, dealing with technical working material and an efficient, goal-oriented mastering of working demands they are perceived as disruptive and the cause of errors" [20] (p. 209).

Additionally, although everyone talks about experience when no one really seems able to state just exactly what experience is, let us begin by elaborating on the conceptual bases of our investigations. We have a fairly clear idea of what work is on the task and activity level. Alternatively, to put it more precisely: We have an image of the manner in which we act and think while working-we all like to see ourselves as objective and logical, as knowing exactly what we are engaged in. It is possible to summarize this idea of doing work as follows:

- Our eyes perceive explicit data and "send" them to our brain. We have a clear objective in mind and work toward it on the principle of: think first, then act.

- All that we do is based on our logical thought processes and the theoretical knowledge we possess.

Machines are inert objects; we relate to them in a purely functional way. According to this idea, this is how we "function": Our eyes act as optical sensors that report data. Environmental stimuli enter our brain and are "processed" there. All this happens based on logical assumptions and theoretically-based knowledge. It is as if we were bipedal, breathing computers. The world around us is perceived as objects and that is also how we deal with it: factually, value-neutrally, and objectively. Hence, we also call this action mode "objectifying." Unquestionably, people can act this way, and there are indeed many daily work situations in which this is the best way of proceeding. Above all, it is whenever we know exactly what lies ahead, when it is clear what the next step should be, that the circumstances surrounding our action can be planned and figured out. However, we also know simultaneously that there is another side to the world and to us as well. The world of work is less and less amenable to being planned out. In many workplaces, the unpredictable has become the new normal. Everything is moving faster and is more complex, so that, at times, no one can say with certainty what the right 
thing to do is in a live situation. Still, a decision has to be made regardless and often without enough time for thinking through all the theoretical possibilities "like a chess player." However, even chess grand masters value both situational awareness and intuition most highly because there comes a point when computation no longer gets them anywhere. Furthermore, this is a case where the possibilities are even circumscribed by a clear set of rules. In operational reality, in contrast, something that no one anticipated is always bound to happen. There is always a first time, always a situation that never happened before, and in which the cookie-cutter approach will not do. This type of situation calls for changing roles: the logical-analytical "computer" turns into the improvising musician who masters his instrument with virtuosity and from the gut. This way of acting is also work, and it is constantly increasing in importance. Mostly, it is the case that the experienced workers are the ones who are able to cope with the unexpected. Thus, work also requires experience.

The concept understands experience neither as basically inferior to theoretical, scientifically grounded knowledge, nor sees it as a quality to be completely replaced by the latter. Subjectifying work action is of great significance as an autonomous form of action and knowledge both for planning and practical action as well as for creative, innovative processes that form the basis for coping with unforeseen circumstances [23,24]. However, an understanding of experience in this sense merely as a set of experiences which have been acquired is not sufficient. The perspective of having experiences also refers to a given moment and situation and to specific action methods used to tackle concrete situations. The concept includes five dimensions of human work action [20]: sensorial perception, the process of action, thought, knowledge and relationship (see Table 1).

Table 1. Dimensions of subjectifying and objectifying work action.

\begin{tabular}{ccc}
\hline $\begin{array}{c}\text { Usual Conceptions of Work } \\
\text { "Objectifying" }\end{array}$ & Dimensions & $\begin{array}{c}\text { and the Role of Experience } \\
\text { "Subjectifying" }\end{array}$ \\
\hline data registering & perception & holistic-sensory \\
planned out & process & dialogic and explorative \\
logical and analytical & thinking & sensing and associative \\
theory-based & knowledge & experience-based \\
objective and rational & relation & empathetic \\
\hline
\end{tabular}

According to this concept, humans approach work with all their senses. Wits and logic alone cannot help us make the right decision in critical situations-intuition, gut feeling, and emotion can also furnish useful inputs. We are not just head but also heart. Thus it is the body that knows and senses, notices and feels its way, remembers sequences. These capabilities often take time to develop; hence, they are encountered above all in experienced workers. Theoretical subject matter knowledge and standardized processes help meet stable, recurring demands. However, it is experience that provides us with the chance to also manage the (as yet) unknown, that permits dealing confidently with imponderables. This is because experience is more than just a static ensemble of routines. Experience also signifies a special way of dealing with things, people, and situations at work. The most important traits of this type of acting and knowing that we term "subjectifying" are:

- A holistic awareness: we hear, see, feel, smell simultaneously-everything may be important, nothing is conclusive.

- An explorative, dialogical process: we feel our way, step-wise. We wait for the reaction; we change our behavior from moment to moment as the situation demands.

- Intuition and feel: often there is no time to think everything through ahead of time. Then we need to have an intuitive sense of the correct thing to do.

- An empathetic relationship: machines may be inanimate objects, but you need to get to know their quirks in the way you get to know a person. Additionally, you need to have a good feel for how to interact with them. 
What we normally understand as work and what role experience plays are two sides of the same coin. It is not a matter of either/or, but of both/and—of work in the sense of rational planning coupled with experience, even, and especially, in assembly work. It is this quality of human ways of working that will keep the human from ever being completely replaceable in complex work environments: the capacity for acting rationally and emotionally, analytically and intuitively, planned and improvisational, as well as by thinking and doing; and, beyond that, knowing what type of situation calls for what way of acting and what knowledge. In juxtaposing subjectifying and objectifying work action, we capture not just two key elements of the "experience-based knowledge work," that is work and experience, but now also a third one: knowledge. For, in the so-named subjectifying mode, knowledge is always already an integral component of acting and hence of work. Work without knowledge is simply inconceivable; work was always also knowledge work, not just since the knowledge society was proclaimed. Admittedly, while in objectifying work activity the theoretical and formalized (technical) knowledge is consulted before the respective action, (experiential) knowledge and action are inseparably intertwined in the subjectifying mode. A rough overview of both modes is found in Table 1.

These fundamental dimensions of experience-and their particular importance in complex and highly automated or computerized work environments-are not new insights in labor and industrial sociology. Already, in the late 1980s, the role of experience in "subjectifying" work action was revealed, first in the study of work in the transition from conventional to computer-numerical controlled (CNC) machines [22] in the processing industry [25] and later in information work [26]. Subjectifying work action, however, is not just an innate ability that individuals "bring with them," so to speak, to work; on the contrary, to be trained, subjectifying abilities in a sense require an opposite number. That which we in everyday language call experience is always something specific. There is no such thing as the assembly experience, rather the special experience in $X Y$ assembly work at company Z. Depending on which technology and products are involved, which process steps are typical, and which organizational form is characteristic, it is differentiated by everything that makes the individual workplace specifically what it is, gathered into the special experiential knowledge and action that is required just in this workplace. Thus, it is only there that it can come into being.

In order to capture this "opposite number" of work means, work objects, and work organization, the study was done with the analytical concept of living laboring capacity [21] which positions the material and social givens of work means, work objects, and work organization as equals alongside the physical and person-specific subjectifying work action. This critical concept defines laboring capacity as the qualitative use value side of human work: The more complex the world that is to be appropriated, i.e., the more dead, objectified labor, the more complexity of social affiliations and relationships in it, the more expenditure and formation of laboring capacity is required in the appropriation process. In digitized work and thus highly developed productive forces, this qualitative aspect of living labor is needed all the more [21].

After what now has been nearly 20 years of research and implementation on the topic of "subjectifying work action and experience", we can make two summarizing observations. First, these qualities of work action are to be found in all areas studied to date, and, beyond that, they are at least as essential for successful work action as their counterpart, the objectifying abilities. Second, of all the empirical fields investigated from the research perspective of the subjectifying work action or work capacity, it is particularly in complex work situations that the special importance of these action and knowledge qualities shows up-making experience, in a way, the "core competence" for dealing with the unexpected and therefore also a guarantor of performance, especially in production [23]. It is therefore hardly surprising that experiential knowledge (whether understood as "tacit knowledge" or implicit knowledge) has in recent years experienced a renaissance in many areas of society, but above all in the areas of work, vocational training, and technology design, and is accepted now to a previously unheard of degree [27]. However, it is still the case that despite its continuing broad acceptance in everyday operations, the quality of experience is frequently downplayed or even discriminated against. 
There are many obvious reasons for this situation, which are connected to the nature of experience; for example:

- Experience cannot be "seen". As long as everything is apparently running smoothly as seen from the outside, its importance simply does not register. Experience is knowledge that has become "second nature", which makes experience so hard to pin down-for instance, by stashing it in databases. That is also why it is so rarely mentioned or even noticed: in breaking in co-workers, in peering over someone's shoulder, during maintenance, and so on.

- Experience is something personal; it differs from person to person because everyone has different experiences. This is what makes talking about one's own experiences and exchanging it so important. On the other hand, this is exactly why this unfortunately happens so infrequently.

- It is skilled workers of all stripes, especially, who regard experience as an almost self-evident element in their skill set that simply goes unsaid. The semi-skilled, for their part, assume that precisely their experience is irrelevant-and this impression is also often conveyed in enterprises.

There are yet two more reasons for the disregard or disrespect for experience: One is the misperception, rife in the literature as well as in practice, which equates an "experience trove" with hardened routines that blind and stultify in dealing with the new and the unexpected. However, the understanding of experience that we have developed here as subjectifying action and knowledge qualities means exactly the opposite, namely experience as a method for doing, as the ability to have (and want to have) new experiences and to apply previous experiences in new ways in coping with unforeseen challenges. The second is that the valuing of experience ultimately is hampered by our industrial history: For many decades, Tayloristic forms of organizing work (and, closely tied with it, also the relevant design principles for production technologies) understood experience not as an instance of managing under uncertainty but rather as a source of unpredictability. The objective was to filter experience as an imponderable element out of the production process as much as possible through formalization and standardization or, better yet, to eliminate it entirely. Interchangeable workers reacting identically by the book every time to invariably recurring, unchanging requirements need anything but individually distinct experience that developed in line with personal experiences. This perspective on experience as a nuisance factor, pointedly formulated as a veritable "enemy" of standardized processes and formalized procedures, still exerts its influence as cultural background on our world and (not just) the (industrial) world of work. As much as this way of seeing stubbornly hangs on, particularly on the decision-making level in enterprises, just as little does it fit modern production requirements. It is in complex, partly highly automated processes that the experience of co-workers facilitates forward-looking detection of looming malfunctions and their eventual impacts-all the way to a complete standstill of work processes-and prevention through early intervention. Along with the ever-rising variety of versions and ever more dynamically changing market demands, assembly work with standardized, even robust processes is no longer immune to the unexpected-to cope successfully with these in an ad hoc manner calls for an experience-based effort. Thus, handling the unexpected is only one facet—experience in flexible assembly systems is, above all, also needed if meaningful standardizations and process improvements are to be pursued in the first place.

Hence, only by acknowledging and promoting the special qualities of experience can their vital complementary function be made use of. It therefore makes sense to take a close look at the expressions of the non-routine parts in assembly work and to highlight something that normally takes place in obscurity and goes unnoticed. In the next chapters, we present first the methodological approach which is then followed by a detailed discussion of the material findings from our studies.

\section{Method and Sampling Strategy}

Following the multiple company case study [28], our findings derive from 62 qualitative interviews in the automotive sector and in the machinery manufacturing branch. These interviews, lasting from 45 to $90 \mathrm{~min}$ each, were complemented by group discussions with employees, management 
and field experts, and some shift-long workplace observations (for an overview of the conducted interviews, group discussions, and workplace observations per case, see Table 2).

Table 2. Overview of empirical basis.

\begin{tabular}{lccccc}
\hline & AUS1 & AUS2 & AUS3 & WSA & EPM \\
\hline Interviews with & 21 & 8 & 8 & 8 & 17 \\
-assembly workers & 13 & 6 & 5 & 6 & 8 \\
-group leaders & 6 & 1 & 3 & 1 & 5 \\
-administration & 2 & 1 & - & 1 & 5 \\
-work council & - & - & - & - & 1 \\
workplace observations & 6 & 2 & 1 & 2 & 3 \\
group discussions & 5 & 2 & 1 & 2 & 3 \\
\hline
\end{tabular}

The branch focus of our research projects was on the automotive and the machinery manufacturing industry in Germany, considering their importance to what is currently discussed in Germany under the term Industry 4.0 [29]. Three companies represent mechanical or electro-mechanical products and are suppliers solely for the automotive industry (AUS1-AUS3); one company produces electronic parts for the automotive as well as for other industries (EPM). In the machinery manufacturing branch we observed one enterprise with a total employee count of under 100 (WSA), producing complex and unique machinery via workshop assembly. This company was chosen as a contrast case for the reason that this kind of assembly is generally regarded as highly qualified and less routinized work than the mass assembly found in the automotive sector. The company sample in the automotive industry consists of four suppliers and represents the typical structures of German assembly locations with regards to employee count, product and process complexity or work organization. For details, see Table 3.

Table 3. Company and workforce characteristics of case studies.

\begin{tabular}{|c|c|c|c|c|c|}
\hline Company Characteristics & AUS1 & AUS2 & AUS3 & WSA & EPM \\
\hline Revenue in Mio EUR & $25-50$ & $25-50$ & $>110$ & $5-15$ & $25-50$ \\
\hline Global workforce & 1000 to 2500 & 5000 to 10,000 & 2500 to 5000 & 100 to 250 & 500 to 1000 \\
\hline Workforce German site & 250 to 500 & 250 to 500 & 2500 to 5000 & 50 to 150 & 150 to 250 \\
\hline Share of personnel costs & $22 \%$ & $24 \%$ & $22 \%$ & $25 \%$ & $20 \%$ \\
\hline \multicolumn{6}{|l|}{ Assembly Characteristics } \\
\hline Product complexity & $\begin{array}{l}\text { simple to } \\
\text { medium }\end{array}$ & medium & high & $\begin{array}{l}\text { medium to } \\
\text { high }\end{array}$ & $\begin{array}{l}\text { mediu to } \\
\text { high }\end{array}$ \\
\hline Batch size/parts & $>1$ million & 10 to $>10,000$ & 50 to $>1000$ & 1 to 10 & 1 to $>10,000$ \\
\hline Assembly system & $\begin{array}{l}\text { Single and } \\
\text { Flow }\end{array}$ & $\begin{array}{l}\text { Single and } \\
\text { Flow }\end{array}$ & $\begin{array}{l}\text { Flow and } \\
\text { U-form }\end{array}$ & Workshop & $\begin{array}{l}\text { Single and } \\
\text { Flow }\end{array}$ \\
\hline Level of automation & medium & medium & high & low & medium \\
\hline Teamwork since & 2000 & 1998 & 1995 & 1990 & 1994 \\
\hline Team size & 10 & 15 & $5-15$ & $1-10$ & $8-15$ \\
\hline \multicolumn{6}{|l|}{ Assembly Workforce } \\
\hline Overall & 150 to 200 & 50 to 100 & 1000 to 1250 & $<25$ & 50 to 100 \\
\hline vocational trained/skilled & $10 \%$ & $39 \%$ & $45 \%$ & $100 \%$ & $22 \%$ \\
\hline unksilled/semi-skilled & $90 \%$ & $50 \%$ & $45 \%$ & - & $78 \%$ \\
\hline Female worker & $21 \%$ & - & $5 \%$ & - & $22 \%$ \\
\hline Migrant worker & $40 \%$ & $44 \%$ & $20 \%$ & - & $8 \%$ \\
\hline Aged under 30 years & $8 \%$ & $28 \%$ & $14 \%$ & $27 \%$ & $8 \%$ \\
\hline Aged over 50 years & $36 \%$ & $28 \%$ & $25 \%$ & $40 \%$ & $24 \%$ \\
\hline
\end{tabular}

Though the initial interviews were conducted in 2006, and the last workplace observations and further group discussions around 2008, the case studies still represent typical German assembly in said branches today regarding the level of automation, the dominant forms of assembly, and the skill variety of the workforce. 
Beyond theoretical sampling techniques according to the Grounded Theory [30] and in line with our research interest, one crucial criterion for selecting adequate interview partners in the five chosen companies was their variety of characteristic assembly work (e.g., the automation level, the complexity of parts and of the assembly process). All gathered and completely transcribed materials underwent an in-depth qualitative content analysis [31] combined with theoretical sensitive coding suggested by Grounded Theory, choosing emergence over forcing empirical data [32].

\section{Assembly Work and Experience-An Overall Look at Our Empirical Findings}

The assembly-experience matrix shown below (see Table 4) presents a condensed depiction of the results of all of our interviews, workplace observations, and group discussions or workshops in the five businesses surveyed. It shows which dimensions of an experience-based knowledge and action (table columns) are used for which requirements during assembly (table rows) and how important each of them is. Our key objective for the empirical work was to determine the expression and importance of the specific work capacity of an experienced assembly worker, as well to capture the situations or dimensions in which experience is seen as important to vitally important. In the interviews, we tried to elicit verbal descriptions of everyday work activities in which phenomena of subjectifying work action played an especially prominent role. These are found aggregated in the columns headed holistic awareness, dialogic approach, associative thinking inclusive of hunch and feel, and, finally, empathetic relationship.

Table 4. The overall assembly-experience matrix.

\begin{tabular}{|c|c|c|c|c|c|}
\hline \multicolumn{6}{|c|}{ Assembly-Experience Matrix } \\
\hline Assembly Overall & $\begin{array}{c}\text { Holistic } \\
\text { Awareness }\end{array}$ & $\begin{array}{l}\text { Dialogic } \\
\text { Approach }\end{array}$ & $\begin{array}{c}\text { Association } \\
\text { and Feel }\end{array}$ & $\begin{array}{l}\text { Empathetic } \\
\text { Relationship }\end{array}$ & $\begin{array}{l}\text { Cumulative } \\
\text { Significance }\end{array}$ \\
\hline \multicolumn{6}{|l|}{ Assembly } \\
\hline Running & + & $\varnothing$ & $\varnothing$ & $x$ & $x+$ \\
\hline Startup & $x$ & + & $x$ & + & $x x++$ \\
\hline Problem avoidance & + & $\varnothing$ & + & + & +++ \\
\hline Problem resolution & $\mathrm{x}$ & $x$ & $\varnothing$ & $\mathrm{x}$ & $x x x$ \\
\hline \multicolumn{6}{|c|}{ Disposition/organization } \\
\hline Group/Team & $\varnothing$ & $x$ & $x$ & + & $x x+$ \\
\hline Performance & + & $x$ & $\varnothing$ & + & $x++$ \\
\hline Quality assurance & + & + & + & + & ++++ \\
\hline Material flow & + & $x$ & $\varnothing$ & + & $x++$ \\
\hline \multicolumn{6}{|l|}{ Innovation } \\
\hline Set up/optimize & + & + & $\mathrm{x}$ & $x$ & $\mathrm{x}$ \\
\hline Learning & + & + & $\varnothing$ & + & + \\
\hline Experience swap & $x$ & $x$ & $\mathrm{x}$ & + & + \\
\hline
\end{tabular}

This assembly-experience matrix in a compressed format shows clearly that experience qualities play a role in all areas pertaining to assembly work. In addition, we can also distinctly pick out the areas in which they are of special or even vital importance: namely during startup, in quality control, and in set-up and optimization of assembly systems and processes-in other words, in the areas that are addressed particularly by the more flexible assembly work design that integrated production systems strive for.

Before we detail our findings along the individual requirement dimensions in assembly work, two major results of our inquiry can be stated: First, even repetitive work is not all that unskilled, provided one makes the effort to observe it in detail and on the level of work action. For handling technology, work routine, product, and breakdowns, experience remains a relevant factor, even when it involves 
seemingly "simple" work. Second, the competency demands relative to disposition and organization are escalating even for so-called unskilled jobs. However, these also have an experience aspect: Quality controls, unimpeded material flow, coordinated group action and performance do not only result from standards, but also and primarily from the workers' subjectifying workarounds. Finally, it quickly became apparent during the survey process that experience not only plays a significant role in learning, in knowledge exchange, and in setting up and optimizing processes, but also that the "unskilled" assembly workers often are more conscious of this role than, for example, their group coaches and supervisors. Despite all the pruning that necessarily goes with a tabular compaction of 62 qualitative interviews from five different companies, the matrix does show that especially the capacity for holistic sensory awareness and an empathetic relationship with equipment, products, and processes is of striking importance. Our analyses, above all, show the holistic quality of these skills: It may be possible to classify the whole range of experience and human capacity for work in each specific dimension of assembly work, but, in daily work, performance without quality is unthinkable, just as a smoothly running assembly operation is inconceivable without anticipatory fault avoidance, and so forth. Many of the passages $\left({ }^{1}[33]\right.$ in the interviews we conducted thus can also be assigned to at least one other dimension. This points out the special quality of experience: At all times and in all places it bears on every action and it is only on paper that it can be deprived of this holistic quality.

\section{The Role of Non-Routine Tasks in Assembly, Startup and Malfunction}

The center of assembly activity is occupied by "actual assembly work": fitting, handling, inserting, and adjusting-seemingly monotonous, undemanding activities. Assembly in its uninterrupted normal operation, in a sense, represents the implicit paradigm of "unskilled work" that glimmers through the debates on this subject we referred to in the introduction. Furthermore, in the interviews on the supervisorial level we often encounter the view that precisely in this context, no elaborate experiential knowledge is needed. However, if we look in a differentiated manner at the demands that are givens in the daily work of a trouble-free assembly operation-and not just in startup or in recognition, avoidance, and remedying of malfunctions-then the profound importance of experience for such seemingly "simple" work emerges clearly. As one worker put it:

"Adjustments like at the [assembly station] can only be made carefully, carefully. How can I explain it? You unscrew it a little, look and see how it reacts, then you turn it back. There and back. Of course you want the best. But you can't get there with just one try. Only in small steps. Sometimes it's more like baby steps. And you're not always going forward, like that. One step forward, two back. Sometimes it's like that. (...) It depends on so much, you know? The parts aren't always the same, and the tools wear down. I don't know what all. Sometimes you get it adjusted on the first try, but maybe the next time you need three times as long. (...) you don't need muscle power, you need finesse, you understand?". (EPM-0505)

With the constant use of all senses, the employees permanently avoid unnecessary downtime and ensure that replacement parts are ordered early. They thereby continually save the company money, something that is usually hardly noticed even by their supervisors. Additionally, if there are disruptions, small ones are usually fixed directly and right away. One example:

"Of course, the problem with these bands are the (...) switches(...). When a part comes up, then it switches, and when it's gone again then it switches back. I think that's the most common source of problems (...). They move, they usually don't have contact, and sometimes they're so hidden that you can't even find them. Yeah, the machine tells

1 For reasons of space, we just replicate some examples of interview excerpts in this article. More are available in the comprehensive version of the study [33]. 
you this and that, there's a problem there, this switch isn't in use. You look, you look, you look everywhere for the switch. Okay, every switch is marked, but sometimes it's so hidden, and sometimes the switch doesn't switch back and then you might have to move it back just one millimeter so that it has enough room to switch back. And you just do that yourself, you don't go get an (...) electrician, that would take way too long. Instead you just quickly grab a ring spanner to open it, move it back a millimeter, and close it up again.". (AUS3-0706)

When intervening and fixing disruptions, timing also plays an important role:

"Yeah, for example, in the machine there's this robot arm that moves the parts from one side to the other, and sometimes it doesn't put the parts down right. And if a part gets stuck once, then you know right away that you need to make an adjustment, otherwise it'll happen the whole day or else it'll all just stop. Because then it will always hit the side, and every time it hits the side it gets knocked out of place a little more. And then it doesn't fit at all anymore and it gets stuck with every part. So it's adjusted right away.". (AUS1-1006)

\subsection{Undisturbed Assembly}

For it is all about just-in-time assembly of what may be highly complicated products in the shortest cycle times with the highest quality. Here work cannot be reduced to a single hand movement; even in the smoothly running assembly operation experienced workers do much more: They perceive the entire process with all their senses (products, parts, machinery, group, etc.). Bodies adjust not only to cycle times, but synchronize with the entire process and the rhythms of co-workers (for instance, on a U-shaped production line). No matter how monotonous the sequence of steps may be, experienced workers remain on alert for the unexpected. They regard the whole as "their" work; every departure from normal is significant. Part of this, for example, is the ability to keep track of the whole environment with peripheral vision, out of the corner of the eye, so to speak, while the inexperienced concentrate more or less exclusively on what they are doing.

In sensory awareness, hearing plays a very special role: Despite the immense volume of the prevailing ambient noise, even the smallest change in the background noise registers with experienced workers and is gauged accurately. With the ability to perceive changes in sound early on and interpret them accurately, the transitions from the (still!) undisturbed assembly operation to prevent malfunctions are fluent. Many changes of sound can be assigned easily and unequivocally to individual processing events, but most often the required perceptual ability is tuned to significantly subtler variations. Hearing is interwoven with a feel for something like a normal or changed texture of the entire noise carpet: The experienced assembler does not hear clearly identifiable tones that point to the cause of a technical defect, but instead knows that the machine has a "belly ache." Something that could at first glance be put down to imprecision or vagueness is exactly the strength of this perceptual ability: Precisely because a fuzzy awareness is possible, any change-even one never before experienced, still unfamiliar-can register very early on. Those with experience have already started listening (up) when approaching the machine or when crossing through the shop floor, so that the perceptual ability is not only or first turned on during the actual assembly hand maneuver. What separates the experienced from the inexperienced assembly worker is, among other things, the former's sensitivity to the change in sound relating to their own process or machine heard over the ambient noise. Decisive in this is the ability not only to perceive the changes but also to classify and integrate them while they are happening. It is not a matter here of an intentional, targeted listening but instead, in a way analogous to the peripheral vision out of the corners of the eye, it requires listening to the whole noise carpet and changes in it as if through "the corners of the ears." Given the short cycle times that are normal in series assembly today, it is not just precision in handling that is called for but also speed. Speed and precision, volume and quality are linked by the experienced worker in a kind of unique overall handling dexterity, not just in the speed of a single hand movement. This type of dexterity, which has a strong physical 
component, is much more than dull routine. It is really an acutely sensing type of action (even when handling component groups, some of which may weigh several kilos) that keeps open all sensory channels for unexpected changes. It is precisely this dexterity, the body-memorized feel for handling and processing, that also ensures that every hand maneuver, every haptic contact in an individual assembly hand movement, and comprehensive quality control (of one's own activity, of upstream processes, of materials used, of process steps, etc.) are all rolled into one. What shapes the total process even more robustly and effectively can nevertheless be felt as stress-related demands by the individual. Still, because this staying clicked in does make functional sense on the material-corporeal level, it gets done; the body can (and "wants to," so to speak) escape the material requirements only conditionally.

Nothing is ever the same. The experienced worker also takes this into account even when the assembly of one and the same part has been running flawlessly for some time. Moreover, it is never just about reacting to potential changes, but about anticipating them: not only does this apply to inter-company upstream processing steps, but even in the event of a tool change on the supplier's side. What passes in assembly work as uninterrupted, normal operation frequently would not be that if experienced assembly workers could not continually master, almost in an offhand way, the minutest actions geared to avoiding and remedying malfunctions that they integrate into their supposedly "repetitive" hand movements. Frequently, this is not even noticed in companies, because, as a consequence of the preemptive handling of malfunctions, they do not "register" as downtime. Let the individual assembly steps, looked at superficially from outside, appear to be repetitive and unskilled: thanks to their abilities, the experienced workers not only master the running assembly, but they also see to it that the assembly line keeps running optimally. They themselves are absolutely aware of the special quality of these experience-based abilities, and they also apply them to new challenges-even when the business environment does not provide sufficient framework parameters, up to and including unpaid time.

\subsection{Startup and Handling Changes}

With startup, it becomes obvious with particular frequency that the assembly workers' experience compensates for standards that are either not set or not likely to be set, for example because the specifications for adjusting the processes and machines are not clear enough or are missing altogether. In part, the parameters are not adapted for the changes in parts or tools, because there is no standard for regularly updating values once they are set; in part, the processes themselves are so fluid (e.g., through waste, quality fluctuations of raw and other materials, and sometimes because of machines that are over 30 years old) that pre-set parameter settings can only serve for gross orientation, and tending to them permanently does not make technical sense either. Whatever the reason, if adjustment parameters are unavailable or insufficient, the adjustment at startup has to rely on the experience of the workforce. Generally, many adjustments during parts changes or startup call for a careful feeling your way, in which sensory awareness as well as handling feels play a special role. Depending on the internal division of labor, complicated adjustment processes will come within the purview of the adjusters and/or group leaders. However, groups in which the experience of several workers makes possible, for example, the parallel adjustment of several work stations during a refitting naturally reduce set-up times and so boost the overall productivity. This is why, wherever feasible, the "unskilled" workers take the adjustment process in hand themselves. As such, experienced workers and group leaders know exactly which adjustment and refit operations require what level of experience. When this is not given its due, things go wrong.

Seasoned workers master conversion to similar or familiar parts effortlessly; this is normal for them. They know the devil is in the details-an omitted end stop can ruin everything. Even the basically familiar series part can differ tomorrow because there have been design changes. The veterans are ready for anything. Particularly in adjusting parameters, when completely new parts are to be worked on, assembly workers and set-up people work together closely. Let their collective practical knowledge be applied to parameter-setting, and this shared relationship with the adjustment process 
will prove especially effective with regard to results. Another decisive advantage of experience takes effect in the startup of new and unfamiliar, possibly even technically more difficult, parts (as distinct from changeovers to familiar parts): Experienced assembly workers do not know fear, but they have respect. They size up the challenge and see their qualitative differences. Furthermore, their experience lends them the necessary aplomb for confronting the challenge.

\subsection{Anticipating and Coping with Malfunction}

Uninterrupted normal operation is anything but pervasive normality; it is more like a fragile state that can be disturbed by imponderables at any time and without notice. This often has to do with the (mostly creeping) wear and tear of the equipment, the handling contrivances, as well as the molds and tools used. However, the unforeseen also arises from variations in materials and the quality of assembly parts, whether they come from downstream processes or from suppliers. Automation can also produce unexpected problems, especially in the relatively tightly chained assembly areas or the so-called bottleneck processes. Particularly in the highly automated volume assembly, the smallest flaws can have far-reaching and, above all, costly consequences: a wrongly-interpreted sensor reading, an initiator that will not switch on, or a relatively minor programming error after releasing a software upgrade, and it is all over. Early recognition of impending malfunctions is one of the most important skills of experienced assembly workers. It is only with experience that varied and unexpected causes of trouble can be recognized by the smallest telltale signs that an outsider would scarcely notice. Key here is also knowing that malfunctions can have the most varied causes: equipment wear and tear and changed materials, supplier parts, or handling automation, etc. The variety of problems can never be completely intercepted with technology - that much sensing technology would make no sense and would be unnecessary in any case. Experienced workers know, for example, what the total noise background sounds like from a particular workstation - they not only catch the slightest deviation, but they can also gauge its relevance.

There is a common notion that, with added control technology and more sensors in the machines and logistics facilities, disruption avoidance could, in a sense, be taken away from the operators and delegated to technology. However, not all breakdowns can be captured in a timely, unambiguous manner and reported by technology. Even in the case of disruptions that can register with IT support, experience-guided awareness of malfunctions is often quicker and more effective. For that matter, control and measurement technology can itself be a source of malfunctions, something that experienced workers know. A persistent unchanged measurement reading, for instance, arouses suspicions, and they have ways and means for quickly checking if the indicated reading and reality are one and the same. Experienced workers thus not only understand the language of the material processes, but also the language of erroneous control signals: they know how to interpret both and to relate them to each other in order to forestall malfunctions before they happen. What "runs along" subliminally as an early indicator of impending disruptions in ongoing assembly work shows up as a key element in problem prevention: Holistic sensory awareness puts the experienced worker in a position to recognize any sort of possible problem indicators so quickly that an actual malfunction can often be avoided by a preventive action. Especially, sensitivity to noise often helps to detect machine wear and tear at such an early stage that an unplanned shutdown can be completely prevented. It is not only machines and tools that are under "observation" by seasoned assembly workers as potential disruptive factors, but also intake, transport, and handling technology, for they are often the cause of entire processes grinding to a halt. The experienced, however, do not just keep an eye on the main press or on the process bottleneck, but also, for example, on the seemingly irrelevant conveyor belts. However, it is not only noises that are attentively monitored in order to register machine wear and tear in time. Where noises cannot help, the whole range of sensory perception takes over in order to recognize any sort of problem by its first signs and treat it seriously. Included here is the look and feel during handling as well as closer observation of machine or process behavior. Should small or larger problems surface, it is not just the practical knowledge of the maintenance person that is in demand, but also the assembly worker's 
experience. The latter takes care of many small details while a process is running, for example the repeatedly needed resetting of end stops. Experienced workers not only master the small intervention, but they are also aware of the limits of their experience. They do not experiment blindly with the equipment and control technology, but can judge when keeping something in working condition is called for. Larger breakdowns can be handled most effectively when maintenance and assembly workers mutually recognize each other's pertinent, specific experiential knowledge and-especially in searching for causes-jointly implement it. Time permitting, the experienced assembly worker profits from the repairs done by maintenance personnel to gain additional practical knowledge of the machines and facilities. Small, seemingly ordinary interventions, for example sign off, are normal practice and are hardly thought of as troubleshooting by the workers. However, they also are only possible when grounded in long years of experience, for it is equally wrong to sign off prematurely as it is not to have enough confidence to sign off (instead calling in the group leader in every single instance, for example). Whether the defect report on the equipment should be taken seriously or can be ignored without compromising quality or the upstream process calls for split-second decisions, which is exactly why they can only be made effectively by someone with experience. The idea is often encountered that especially highly-automated facilities can purposely be staffed with the less experienced, since these facilities generate error messages on their own in case of process and quality deviations. However, interpreting these error messages is not that simple. Recognizing their real significance is possible only on the basis of grounded experience. Indeed, experienced workers in assembly regard the necessity to intervene as an integral element in their work, as a "minor detail" of which nothing much is made. That does not change the fact that these steady interventions are what keeps larger disruptions from happening in the first place.

The numerous, seemingly simple, standard errors that are experienced as normal and that can be easily fixed must not blind us to the unforeseen errors. Experienced workers are aware that their standard fix does not always do the trick and that a same phenomenon may hide totally different remediation requirements. This ability to differentiate, this knowledge of the variability of what causes defects, and hence also the variation in remedial measures, only accumulates over time-it simply is a matter of experience. Just as relevant as a timely recognition of a malfunction about to happen is choosing the right time to intervene. Especially with wear- and process-related disruptions, a timely intervention can prevent serious, costly repercussions. The "low-skilled" assembly workers sometimes know more tweaks and more effective ones, resulting from their specific experience with normally operating equipment and processes, than the fitters or the group leaders. Additionally, they absolutely think in a cost-conscious manner in these situations-a skill that supervisors often deny in "their" assembly people.

\section{Assembly-Embedded Interactive Tasks: Disposition and Organization}

Besides the actual assembly work, the "extraneous" plays an ever more important role, especially in the case of modern, flexible assembly processes. Our inquiries show that experience is significant not just in working with technology, machinery, and products, but also, and increasingly so, in relation to the group and group action, performance, quality assurance and materials flow. Disposition and organization in recent years have clearly grown as requirement dimensions and belonging to them is not only a new canon of technical knowledge but also specific manifestations of experience. Experience matters in work life not just in relation to dealing with technical things; the corporate social environment is also the source of experience as well as an area for its application.

How important experience is within the whole group for performance and quantity is shown by this quote. Here there is a critical reflection of how much the person is an appendage of a situation he is not controlling and how much the pressure increases when switching to U-shaped assembly, but the quote also shows: This knowledge about the person's position in their own production process does not lead to subversive behavior. Because the required synchronization makes functional sense from 
the worker's perspective on a material-physical level, it is done; the body can (and "wants to," so to speak) escape the material requirements only to a limited extent:

“Well in [assembly step V] it's harder, let's say, experience is really helpful there. Because there are different [assembly] times, and there you have five machines: One runs three, the other runs five minutes. Of course it would be best if they were all the same, but that hardly ever happens. And with experience, you know: How long can I let a machine stand so that it doesn't cool down too fast, because for [this assembly step] that's fatal, then I've got a mess or the parts are bad because they're error-prone. And then you just have to find a compromise: Do I maybe let that one stand once or this one for a little bit, then I do that one and then at some point I've got a rhythm and then it's easier for me. It should be done in a certain rhythm. I can close them all in a row or I run to that one then to that one and to that one. I run around like a monkey. Well, of course the optimal thing for the machines and for the output is the monkey. That's why today we're moving away from that, I mean, we're moving away from saying that these five machines are yours. Instead, we say there are the 20 machines, now the five of you go over there and work. It doesn't matter who does what. Whoever is closest works on the next machine. That's the optimum, really. That's what's the most productive. But then you're really under pressure, so we're already saying that no one can fall sleep there anymore.". (AUS1-1606)

The rhythmical coordination between the machine's rhythm and cooperation in the group is more necessary and more stressful in a U-shaped assembly. The workers see that and respond to the demands by behaving with more solidarity toward one another:

"For example if the press I'm at, this one here, if it's closed and I help my colleague and during that my press opens, then I'm the one who goes there. So I help all my colleagues until my press opens, and I see it, and then I go, then I'm the one who goes to that press. He keeps doing his work. It's supposed to be that we all go from one press to the another, walking around. But that doesn't work. If presses are here and here and here, then you're supposed to always be spinning around, but that doesn't work. Because we have presses that run between four and eight minutes. (...) That's a really big difference. Six minutes, eight minutes is what we have here. And that's how they want it, that's why they put these tables like this, but that doesn't work. That's just theory. On the computer. But that can't really be done in real life.". (AUS1-0406)

\subsection{Non-Routine and Interactivity in Group or Team}

Moreover, in assembly the most important social environment is the individual work group. In assembly group works, experience relates not only to the use of so-called "social skills." Certainly, it is important to be team-capable, to act in a collegial manner, resolve conflicts objectively, listen actively, and so on. Of course, experience plays a role in these forms of social coexistence as well. However, an assembly team is not only about social cohesion. It is also and especially a work connection. To perceive with all the senses is an important dimension of experience-based action. It is meaningful not only in relation to early problem prevention, but also when it comes to group relationships among colleagues. Sensing in a timely fashion who needs help, or seeing with your peripheral vision that a new colleague's workstation is too elaborately arranged ergonomically, too, is a question of experience. In certain types of assembly work, such as on U-type assembly lines, it is all about cycling smoothly into the technical processes and into the group. That is achieved only with a highly developed holistic awareness. Experienced individuals move as a group in synch with short cycle times, often in a confined space similar to a skilled soccer team. Only when a player is substituted and the rhythm is lost does the extent to which a collective body's sense and coordination capability are in play become apparent. Experiential knowledge is always individual-not everyone in a group can have accumulated the same experience. This diversity turns into strength when all are aware of 
their own experience and that of the others, but also of everyone's limits. This is a particular challenge for an experienced group leader. In a successful shared group experience, not only do quality and piece counts click, but the entire group's experiential knowledge also grows. In this context, the ability to relate in a shared experiential manner to the work object is often more important than "just" the social level of collective skill. This simultaneous clicking in with technical processes and the group ensures not only that the work process is mastered, but planning errors or shortfalls in fine-tuning are compensated for. Organizing the rotation within the group is therefore not only a question of a fair distribution of the workload; it also depends on gauging individual skills and experiences. An experienced group will factor both criteria into how it organizes its rotation.

Productivity results not just from efficient flows, standardized processes, and fully developed technology. The piece counts and cycle times demanded by today's market pressures cannot be achieved without the experienced assembly worker. Whenever skill requirements in assembly work is the subject, the issues of performance and productivity are seldom included in the discussion. Performance and productivity are seen as basic and self-evident framework conditions and as resulting from the most optimal work possible in engineering and construction, in job planning and production control. According to this view, assembly as supposedly unskilled and monotonous routine work in the end is only the executing organ whose actors are interchangeable at will. Even when the decision-makers in an enterprise are aware of the potential impacts of shifting or temp work and that experience also is a significant element in performance, experience is often downplayed. The workers on the assembly line, however, know that whoever is the most experienced on a workstation guarantees not only the best quality on it but also the highest piece counts. The supervisory level frequently underestimates the engagement of the "unskilled" assembly workers. Especially the group leaders or team leaders know quite precisely from experience which seats can be assigned to the less experienced and on which stations highly developed experience is indispensable. Knowing that a job rotation would not work in practice is often related to the awareness that the group's overall productivity and/or quality would suffer in the short run if a change were made. Seasoned workers apply their skill and knowledge in every situation and thereby ensure quality and productivity. These are not just "afterthoughts" of technical-organizational flows but also flexible guarantors of the efficiency of the whole.

\subsection{Non-Routine Capabilities Ensuring Performance and Quality}

OEE, which stands for overall equipment effectiveness, is calculated from key performance indicators such as machine availability, machine performance level, and so forth. However, a key factor in optimal OEE stems from something that is difficult to put a number on and simply cannot be captured in key performance indicators: worker experience. Without experience being permanently fed into ongoing assembly and startup, the cycle times and piece counts demanded today are in the long run unachievable. Without the ability to make the right move to prevent impending malfunctions-even under time pressure!- - high productivity is not sustainable. This experience is also indispensable when it comes to performance. This does not apply only to piece counts; experience is also a material performance factor in specialty mechanical engineering. What matters there is meeting deadlines and as rapid an implementation as possible, capabilities that are tightly coupled with the experience backing them up. One reason that experience and performance are so tightly interlaced resides in the speed and sleepwalker-like facility in performing the individual hand movements. This is an ability that seasoned workers will always possess, giving them an advantage over new hires or the less experienced.

The experienced, moreover, never sacrifice quality on the piece count altar. Speed is not allowed to become a fetish, but instead, when, for example, changing starting conditions bring with them differentiated and action sequences of varying durations, these will be executed with the necessary caution. Experienced workers pull off this permanent, situationally conditioned balancing act because they not only can perform the individual hand maneuver quickly and precisely, but also because a 
hand movement is more than just a hand movement. It is also always a subliminal quality control that often involves sufficient and simultaneous problems preventing micro-moves "at the margin" or, better said, "on the fly".

Complex products, such as those manufactured in Germany, are quality products, and demands for quality will only continue to increase. Global competition shows that, today and in the future, it is not just about competing on costs, it is also about competing on quality. Crucially, quality is determined at the worker level and connected with their skills, an insight that has not been challenged for many years. This is why many quality control measures, such as static process control (SPC), self-checking by craftsmen, quality circles, and quality management, go hand-in-glove with worker training methods. However, quality cannot be assured only by methods or by conveying theoretical knowledge. Quality is the dimension in assembly work in which all kinds of experience-based knowledge and action play an indispensable role. A holistic awareness, a dialogic dealing with product and process, a feel for material and flows, as well as a real relationship to handling things are all necessary for guaranteeing high quality in lasting fashion. Quality production, thus, is not only important on the level of what is an almost "ordained" quality assurance.

Experienced workers pick up possible errors with all their senses, literally with every fiber of their bodies. Reaching into the Kanban basket, loading the machine-every haptic contact, every glance out of the corner of the eye is ongoing quality control. Here a changed metal surface attracts attention, there a problem burr is noticed, or a drill hole is seen to be missing. All this happens practically in the blink of an eye, almost unconsciously, with every move of the hand, day in day out-and all of it is possible only against a background of highly developed experience. Only someone through whose hands much quality has flowed, only someone who has already experienced the most varied defective parts has accumulated the experience for this kind of holistic quality control. Not only does this prevent that worker's own mistakes, but it also catches errors from preceding processing steps and intuits potential mistakes by the colleague in the next seat. Add to this something akin to a collegial quality understanding, for example, when a worker hands off the parts in such a manner that the left-handed colleague in the next station gets at them better. To take responsibility for overall quality in this sense comprises much more than what can be depicted by quality KPIs (Key Performance Indicators).

\subsection{Mastering the Material Flow and Compensating for ICT Flaws}

However, if there is a shortage of this kind of experience in assembly, today's minimum parts-per-minute rates are not achievable. There is no such thing as a zero-defect car without a maximum of experience on the employee level. Integrated production systems aim not only at optimizing assembly processes per se; the continual improvement with the objective of an unimpeded material flow is just as crucial. Highly variegated solutions have been found, depending on the type of product and assembly technique. There are Kanban systems that even tie in the suppliers. Then there are the so-called milk runners, individuals tasked with cyclical material provisioning and who therefore relieve the groups of that burden. In high volume production, the internal business logistics, in part, are even outsourced to external service providers.

In one-of-a-kind ("one-off") and batch production assembly, in turn, assembly workers are responsible for not only the material flow, but even material procurement. While in the course of semi-autonomous group work and lean production the responsibility for material flow was very firmly shifted to the group, now the tendency is to relieve the group of it. In addition, ICT systems for production planning and control hold out the promise of real-time and precise monitoring of material flows and warehouses, implying that no order will be released until all necessary parts are readily available. If all these logistical, organizational, and ICT measures were to function smoothly and interact seamlessly with one another, with all actors working well together, from suppliers to the logistics provider to the milk runner and the employee in procurement-who ultimately enters the basic data relevant to material flow in the ICT systems-then the demands on the assembler relative to material flow would be vanishingly small. 
However, the industrial reality looks different. The supplier parts may be in house, but not in sufficient quantity at the right time in the right place. Milk runners may give it their best, but then they cannot be there at the decisive moment since their "functioning" depends on too many external conditions. The difference between the readout of the Product Planning and Scheduling Systems (PPS) and the real material situation unfortunately empirically is not an exception but a daily fact in many enterprises, as is also the often time-intensive search for the missing parts that ensues. Those with experience know all about this "completely normal insanity." Their holistic awareness relates not to assembly itself but the whole ball of wax. A Kanban basket that for too long has not been replenished, a harried milk runner, intuition in looking for missing parts: seasoned assembly workers conceive of it all as an obvious part of their work.

It is simply true that assembly work can run undisturbed only when no imponderables arise from incongruous real and computerized processes, or if the resulting uncertainty does not impact the flow of production. Exactly this kind of imponderable is on the rise: time and again, experienced workers have to improvise on the level of the real process. An example that repeatedly crops up empirically is deficits in capacity and product planning that, when they manifest themselves, must be improvised for situationally and ad hoc by experienced workers. Only in the rarest cases are these deficits the result of employee mistakes in production planning. Instead, what happens here is that the basic, materially determined parameters, which are indispensable for meaningful planning, are not entered into the planning system as actual data-leading repeatedly to many cases where the times stored in electronic production plans for individual work runs do not agree with times actually required. This then coincides - frequently with cumulative effect-with requirements that are not capable of being integrated in a timely manner with capacity planning and that simply cannot be compensated for in terms of substance (e.g., problems with individual equipment, delays, substandard supplier parts, and the like).

Typically, to top it all off, there is the search for what could be called computer-generated missing parts, to coin a phrase. This refers to parts which, according to the PPS or Enterprise-Resource-Planning Systems (ERP), should be available in sufficient piece count and even at the right time at the right place for a pending order-at least that is what the display says. However, too often the displayed normal status does not really exist. The parts are neither to be found on the spot nor in the indicated storage location. Should the planning horizons generated by the sales logic then remain in the systems as constructs that are difficult to work around, the forecasts suggested via ERP and PP\&C then tend to turn into barriers to real, functioning plans. Failures in planning can only be compensated for by experience in the work process.

\section{Innovation and Organizational Learning}

Assembly work even plays a role in innovative processes, and assembly workers are involved in optimizing and organizational learning measures. Their experience is needed in configuring and ramping-up of new assembly lines, they are inclined to continually optimize the assembly process, and last but not least, they play an important role in transferring their non-routine capabilities and the related so-called tacit knowledge towards other workers, for example in assembly sites offshored to low-cost countries, to assembly line planners, and to experts in automatization-even at the cost of losing their own jobs.

\subsection{Configuring and Optimizing Assembly Lines}

Constantly configuring and optimizing processes is unthinkable without the specific experiential knowledge of the individual assembly worker. Many companies have realized this and involve the employees earlier than ever in process configuration and optimization. Even when it comes to conceptualizing facilities and shifting workstations, their experiential knowledge is purposely brought in and used in a way it never used to be. Finally, whether it is Kaizen and CIP (continual improvement process) or a company-wide employee suggestion program, all these systems thrive on the input of 
the assembly workers' practical knowledge. This they provide indeed. Seasoned workers know not only about the relevance of their experiential knowledge applied to configuration, but they volunteer it. They regard configuration and optimization not as special tasks but as integral elements of daily work, not only in the operational "small potatoes" at their own workstation, but also by taking part in overarching optimization processes or by pushing for them. A natural optimization strategy relates to the level of the item count. Experienced assembly employees also take care of that, even if in doing so they raise their own time pressure and that of their colleagues. Seasoned workers not only bring their experience to bear on configuring individual hand movements in their workplace in its narrowest sense, but also they eye up entire processes when it comes to optimization. Often the configuration and optimization activities of experienced assembly workers compensate for design flaws in equipment or instruments, and in the area of specialty mechanical engineering even for design flaws in the products themselves. What matters most is that experienced individuals not only have the ability to configure and optimize processes but also want to exercise that ability. Empirically, we found many indications of the kind of self-starter engagement with and enthusiasm for what might be called "grass-roots" optimization-a potential that should not be stifled by too much top-down standardization. This quote shows how much the simple assembly worker participates in the continual optimization of processes. He not only thinks of the ideas for improvements himself, he also prevails against his supervisor and in doing so even initiates a process of proactive maintenance:

"There are outlet valves, they open when the perc should be let out, and they close when the perc comes in. There's a notch in this valve, and if there's just a tiny crack in it then all the air gets mixed up. And then it doesn't create the vacuum down that it needs. The outlet valves is what that is, and we've got 40 of them. So, and now figure out: Which one is it? And how do we do that? Yes, we do it this way: We know what the problem is, we've had it before. And we record it. Careful, concentration is too high, then I made my notes. And then we said to the boss: Hey, look, this doesn't work, of course we can assume that it's this one, but it doesn't have to be that one. And we did, great! We think that it's that one, then it was drilled out, but: nothing, you can't see anything. It can't be that one. So then we said: Look, it works great, the machine, everything's ok, but it has these weak points, the valves, how about, even if things are going well, how about we switch them out every six months. It's done on a Saturday, the mechanic changes them all out, and then it's guaranteed that we won't have a malfunction. Because the wear and tear happens, and now we say: Every six months we change all of them out.". (AUS1-0606)

\subsection{Learning and Being Able to Gather Experience}

Experience is not simply switched on or off. It is not only the spontaneous consequence of putting in many years at one and the same place of work. Experience is also a question of attitude and a method of doing. The experienced are not only sure of how important their experience is to the work process, but they also develop a feel for the paths to learning, a highly individual way of "picking up" experience. It is learning by doing, and experienced workers organize their doing; they seek out opportunities for new experiences instead of avoiding them. In this way, any work situation can turn into a learning situation; for example, maintenance repairs on their own workstation offer totally different ways to experience the machine than while it is running. Additionally, when a colleague is doing rework, she pitches in and, by doing so, takes the initiative in looking at the upstream process. The seasoned understand the significance of such situations and take advantage of them-if allowed to. Regrettably, the piece count pressure is often so great that such valuable situations for learning by experience cannot be exploited sufficiently. Also, many in-house continuing education activities are oriented toward formal teaching of theoretical knowledge and too seldom toward criteria for an experience-guided learning. In contrast, there is no need to explain to assembly workers how learning from experience differs from other learning techniques. They have a very well-developed sense that gathering experience and learning during the work process are two sides of the same coin. Experienced 
employees doing assembly also know that experiential learning can already start when watching others at work. The key element in experience learning, however, is and will remain hands-on doing: the haptic handling of work objects, the deploying of sensory awareness, gaining body intelligence and a feel for materiality during the work process. Many interview excerpts illustrate that assembly workers are very much in the know about this access to learning and also apply this knowledge purposefully. In learning and experience accumulation, the important thing is to confront things, to get into them, experience them hands-on. Many interview passages show that assembly employees often know more about successful mechanisms and feasible ways of experiential learning than many vocational teachers.

Combined with this attitude of being open to experience comes being conscious that what is learned by hands-on doing is retained best-it imparts certainty and authority in dealing with the unforeseen. They treasure experience and therefore seek out learning situations that make it possible for them to experience new products or equipment, for example, from the ground up. Ultimately, learning from experience also means learning from problems that have been solved. While on the discourse level within enterprises an ever more strongly expressed discrimination of the word "problem" seems to be being formulated, experienced assembly workers recognize the value of problems for gathering experience. Not just the actual cause of the problem can be of significance here-experiential learning also feeds on the large and small problems that paved the way to a solution. Many descriptions show also how the specific improvements by the workers have consequences including for how the machines are built. The machines improved by this practical knowledge are transferred to other locations, and the practical knowledge that went into them, too, as this worker discusses:

"Well I guess you could say they also transferred our experience. Because we improved our machines here, [laughs] and when they're dismantled, they're gone with the improvements, I guess you could say. Just by doing that the know-how is lost, it just goes along with the machine, and they might not give a thought to where it's coming from, but they can take advantage of it when it's already built into the machine.". (AUS1-1406)

\subsection{Sharing Experience and Collective Learning}

Exchanging experiences is also part of experiential learning. Fundamental here is being aware of how special and important one's own experiential knowledge is-and not just one's own, but also the experiential knowledge of others. Readiness to share this knowledge does not have to be awakened in the experienced, for they know that everyone has their share of it. If this readiness is lacking, it is usually operationally conditioned, for instance due to a group leader who does not nurture but monopolizes everything herself, a group climate based on competition, or piece counts and cycle time pressures that crowd out everything else.

It happens that passing on experiential knowledge occurs best in a concrete situation and by direct demonstration, by mimicking, and by shared hands-on doing. That takes time and opportunity. The situational passing on of experiential knowledge during the work process is the most effective way to learn collectively: no continuing education module, no group discussion, no written best practice can take its place. As part of a successful exchange of experience, one has to approach more experienced colleagues to share theirs. That in itself calls for experience-knowing who has the deepest and the most helpful store of experiences. This experience then is called on situationally when it is needed. Of course, it is not just relevant to gather experience from the right source, that is from the colleague who has pertinent experience with the problem at hand. It always takes two (at least) for an exchange of experience.

Even the workers' own learning is done less through the company's training sessions and more by actively picking things up on the job:

"Yeah, the training sessions from the manufacturer, they're not really that helpful. It's just general information, I'd say, like: Look, there's this part, there's this part, that works 
like this. I don't need that. I just need to be at the machine for a half an hour and then I know it myself. There aren't any special training sessions from the manufacturers. If there are problems then there's the manual, I'd say, or the user's manual, but especially then, experience plays a big role. I'd say in our area experience plays a really big role, without a doubt, yeah, and the rest is learning-by-doing.". (AUS1-1306)

That means there has to be the right attitude on the other side, that of the experienced person. Not only must employees want to pass on their experience; they must be able to judge who is less experienced and what experience the other person lacks. Being prepared to exchange information does not stop at the group boundary or at the end of a shift. Among the employees, this willingness includes a great deal, such as experiences with the equipment manufacturer, sharing about shift and group boundaries, all the way into time after work. A typical example of sharing experience at shift change shows that, besides the entries into the shift log, those hard-to-formulate experiences with the process-related state are passed on. Exchanges of experience gained are regarded as completely normal elements of work activity, and, where necessary, even to the point of "hot wiring." Experience exchange functions not only verbally, but is often coupled with a demonstration on the object and with mimicry. Wherever possible, experience exchanges interlace with shared hands-on doing.

\section{Conclusions}

High volume assembly, one-off assembly in specialty engineering shops, line or U-shape assembly, highly automated or manually intensive: assembly work covers a wide spectrum. The differences are immense and vary not only by assembly type, but also at least as markedly by automation level, batch sizes, product complexity, technologies deployed, forms of group work, and so on. The results presented here show that all dimensions of experience are encountered in every kind of assembly work, and thus assembly work should not be labeled as merely routine work. Clearly, the way experience is expressed can differ significantly. However, for these differences the type of assembly is no more important than, for example, the product complexity or the degree of automation.

It is also a fallacy to think that experience in one-off assembly is superior to line assembly. In both types of assembly, the features of experience are expressed in the same dimensions: holistic awareness, dialogic approach, association/feel and empathetic relationship. Time pressure is less pronounced in workshop assembly and there is less standardization of work processes, and this also means that errors do not necessarily entail immediate consequences for costs. A great deal can be straightened out in workshop assembly by improvising or spontaneous changes in work sequence and the like, a freedom that is absent on assembly lines. Here experience has to function "on the spot." As we tried to show, human experience will be still needed on the future shop floor. With new cycles of automatization ahead, one still could ask why workers are giving in this compensating and thus neglected role, or if there is a "message of resistance" or new Luddism to expect [34]. However, this last interview quotation illustrates how human experience, worker cooperation and economic competition seem to be intertwined, at least today:

"But what is such a situation for us or rather that there is a process-suited flow within the team or the production line when one converts. That is to say, one doesn't only have this type on the assembly line, one also has [the units R]. And then the team has to organize itself well to assure the process, that is if we compare ourselves to other shifts. I have already worked in all three shifts. And it's not the same everywhere. They don't organize themselves well. That is to say, it is actually the worker at the first station who must then reconvert the cars and refit the body, that is, he has to exchange all the fixtures on which the body is placed, he has to exchange them and fit those for [the units R]. But when he has so much to do, it comes to a stall somewhere else, of course. So someone has to go there where it is piling up and then do this work. And when it looks better he can go back to his station. You know, as a team one has to steer the processes oneself. If the team does not 
control it right, the process isn't smooth anymore and one can ... or one loses a lot of time because of it". (AUS3-0306)

Our research findings on the role of experience as a genuinely human quality in various modern forms of assembly shed new light on actual predictions concerning employment effects triggered by the new automation paradigm that, in Germany, is discussed under the label Industry 4.0 and that is addressed in the international discourse as the manufactural Internet. The most prominent cited study here is that of Frey and Osborne [8], which estimated that in the coming years, 47\% of US jobs could be automated through the application of new digital technology. Other authors, too, have recently revisited a historically important argument that had been almost forgotten (also in the sociology research on work): technological progress may well lead to the elimination of the need for human labor [35-37]. Today, as so often during previous phases of rapid technological change, this argument is either positively associated with the hope that monotonous and physically strenuous work will finally be replaced with creative work (and opportunities for training workers to be more creative), or it is negatively associated with higher unemployment and widespread workforce de-skilling. These two diametrically opposed discourses inevitably pop up together whenever the connections between technology and work are discussed. Negative and positive scenarios alike, although differing in their forecast, are more similar in their underlying assumptions: first, they underestimate the role of human experience in today's assembly work; second, they consequently categorize assembly as mere routine work; and, third, they see assembly work as easily susceptible to replacement-especially by the new robotics. As we have seen in the history of industrial robotics, automatization will be driven not only by technological opportunities but also and perhaps even more by the accompanying economic promise. As Horst Neumann [38], the former CHRO of Volkswagen summed up: Robots run 35,000 h with overall costs from 100,000 to 200,000 EUR (maintenance included). That equates to 5 EUR per hour, so he hopes repetitive routine work can be substituted and the German demographic problem to a certain extent solved.

This article started with the WEF 2016 prognosis on job losses in the years to come. Earlier documents this world leading economic and political think tank has published describe a "blended workforce" and proclaim a shift towards an integrated digital and human workforce; the term "digital labor" is a specific reference to the use of digital technologies to take over work once done by humans: "smart sensors, machines (e.g., robots) or intelligent systems that can do parts of the jobs that only humans used to do" [39] (p. 28). Automation always has aimed and always will aim to substitute for human labor, and with new robotic concepts ahead we will see many attempts to do so in the world of assembly. However, the limits of automation are to be seen after decades of robotic use in industry: coping with imponderables, the flexibility and ability to adapt, the unlimited variability of behavior and tacit skills and body intelligence-all these dimensions of genuinely human work cannot be replaced by robots. The research results presented here instead hint at how deeply complex work environments are dependent on humans and especially on their experiential capabilities which could be considered the opposite of mere routine. The findings thus add to Moniz' considerations about the intuitive side of the interactions between robots and humans [40]. This article echoes for robotics in assembly what other authors conclude for service robotics, namely that less qualified jobs are susceptible to replacement by robots, but nonetheless technology " (...) will never evolve to the point where average human being's work can be automated. The economy creates and produces in all circumstances and all times new jobs for people with an average human knowledge and skills" [41] (p. 20). This citation refers to employment dynamics as a whole and in the long run. For the concrete worker in assembly today, the increased use of robotics still gives reason to worry about her own employment prospects. Although the results discussed here suggest that robotic automation in assembly needs more human qualities than is usually assumed, robotic automation certainly aims to change the human quantities on the shop floor: In 2014, the average global robot density (usually defined as the number of multipurpose industrial robots per 10,000 persons employed in manufacturing) has amounted to 66, reaching far higher figures in leading countries 
such as the Republic of Korea (density of 478 in 2014) and Germany (292) [42] (p. 14). For 2015 to 2018, the IFR forecasts a further double-digit growth and proudly foretells that "industrial robots are conquering the world" (p. 18). Facing these figures, we can only hope that the automation paradigm guiding this trend will finally overcome a shortsighted "abracadabra" of substitution-based function allocation methods [43] and acknowledge the variety and quality of human experience and living labor as the crucial source for human-robot collaboration. What was true for the 17th century [44] seems to be much more the fact today, with experience as a dynamic resource instead of static routine: human laboring capacity, in all its diverse and under-appreciated facets, is a major reason why individuals can learn to deal with complexity and unpredictability. As we unfolded here, and as can also be measured quantitatively [9] laboring capacity enables us to engage the increasingly significant "ironies of automation": "[t]he more we depend on technology and push it to its limits, the more we need highly-skilled, well-trained, well-practised people to make systems resilient, acting as the last line of defence against the failures that will inevitably occur" [45] (p. 65, our own italics).

Acknowledgments: This article is based on work within the joint projects "WAMO_Erfahrungsbasierte WissensArbeit in flexiblen Montagesystemen" [experience-based knowledge work in flexible assembly] and "Rakoon-OpenOrganisation", both funded by the Federal Ministry for Education and Research (BMBF) and the European Social Fund (ESF), and supervised by the Project Management Agency Karlsruhe (PTKA) and German Aerospace Center (DLR). The author would like to thank all workers who contributed insight to their experience, and all the editors and reviewers for providing helpful comments on earlier drafts of this paper.

Conflicts of Interest: The author declares no conflict of interest.

\section{References}

1. WEF. The Future of Jobs. Employment, Skills and Workforce Strategy for the Fourth Industrial Revolution; World Economic Forum: Davos, Switzerland, 2016; Available online: http:/ /www3.weforum.org/docs/ WEF_Future_of_Jobs.pdf (accessed on 30 January 2016).

2. Frick, W. When Your Boss Wears Metal Pants. Insights from the frontier of human-robot research. Harvard Bus. Rev. 2015, 96, 84-89.

3. Bloomfield, B.P.; Vurdubakis, T. Mors ex Machina: Technology, Embodiment and the Organization of Destruction. Organ. Stud. 2015, 36, 621-641. [CrossRef]

4. Cohen, N.S. From Pink Slips to Pink Slime: Transforming Media Labor in a Digital Age. Commun. Rev. 2015, 18, 98-122. [CrossRef]

5. Bessen, J. Toil and Technology. Finance Dev. 2015, 52, 16-19.

6. IFR. World Robotics. Industrial Robots 2014; Frankfurt, M., Ed.; International Federation for Robotics: New York, NY, USA, 2015.

7. Nye, D.E. America's Assembly Line; MIT Press: Cambridge, MA, USA, 2013.

8. Frey, C.B.; Osborne, M.A. The Future of Employment: How Susceptible are Jobs to Computerisation? Available online: http:/ /www.oxfordmartin.ox.ac.uk/publications/view/1314 (accessed on 30 January 2016).

9. Pfeiffer, S.; Suphan, A. The Labouring Capacity Index: Living Labouring Capacity and Experience as Resources on the Road to Industry 4.0. Available online: http:/ / www.sabine-pfeiffer.de/files/downloads / 2015-Pfeiffer-Suphan-EN.pdf (accessed on 30 January 2016).

10. Walker, C.R.; Guest, R.H. The Man on the Assembly Line; Harvard University Press: Cambridge, MA, USA, 1952.

11. Levitt, S.D.; List, J.A.; Syverson, C. Towards an Understanding of Learning by Doing: Evidence from an Automobile Assembly Plant; National Bureau of Economic Research: Cambridge, MA, USA, 2012; Available online: http://www.nber.org/papers/w18017.pdf (accessed on 30 January 2016).

12. Autor, D.H.; Levy, F.; Murnane, R.J. The skill content of recent technological change: An empirical exploration. Q. J. Econ. 2003, 118, 1279-1333. [CrossRef]

13. Fernández-Macías, E.; Hurley, J. Drivers of Recent Job Polarisation and Upgrading in Europe: Eurofound Jobs Monitor 2014; Eurofound: Luxembourg, Luxembourg, 2014; Available online: http:/ / eurofound.europa.eu/ sites/de-fault/files/ef_files/pubdocs/2014/19/en/1/EF1419EN.pdf (accessed on 30 January 2016).

14. Polanyi, M. The Tacit Dimension; Peter Smith: Gloucester, MA, USA, 1983.

15. Dreyfus, H. What Computers Still Can't Do; MIT Press: Cambridge, MA, USA, 1992. 
16. Kusterer, K.C. Know-How on the Job: The Important Working Knowledge of "Unskilled" Workers; Westview Press: Boulder, CO, USA, 1978.

17. Zuboff, S. In the Age of the Smart Machine: The Future of Work and Power; Basic Books: New York, NY, USA, 1988.

18. Suchman, L. Human-Machine Reconfigurations: Plans and Situated Actions; Cambridge University Press: Cambridge, MA, USA, 2007.

19. Strauss, A. Work and the Division of Labor. Sociol. Q. 1985, 26, 1-19. [CrossRef]

20. Böhle, F. Relevance of Experience-based Work in Modern Processes. AI Soc. J. Hum. Cent. Syst. Mach. Intell. 1994, 8, 207-215. [CrossRef]

21. Pfeiffer, S. Digital Labour and the Use-value of Human Work. On the Importance of Labouring Capacity for understanding Digital Capitalism. tripleC 2014, 12, 599-619. Available online: http:/ /www.triple-c.at/index. $\mathrm{php} /$ tripleC/article/view/545/610 (accessed on 30 January 2016).

22. Böhle, F.; Milkau, B. Computerised Manufacturing and Empirical Knowledge. AI Soc. J. Hum. Cent. Syst. Mach. Intell. 1988, 2, 235-243. [CrossRef]

23. Böhle, F. Management of Uncertainty. A Blind Spot in the Promotion of Innovations. In Enabling Innovation. Innovative Capability — German and International Views; Jeschke, S., Isenhardt, I., Hees, F., Tantrow, S., Eds.; Springer: Berlin, Germany, 2013; pp. 17-30.

24. Perrow, C. Complex Organizations: A Critical Essay; Random House: New York, NY, USA, 1986.

25. Bauer, H.G.; Böhle, F.; Munz, C.; Pfeiffer, S.; Woicke, P. Hightech-Gespür. Erfahrungsgeleitetes Arbeiten und Lernen in hoch technisierten Arbeitsbereichen; Bertelsmann: Bielefeld, Germany, 2006.

26. Pfeiffer, S. Ignored and Neglected-Work in Cybersociety. Exploring Cybersociety. In Social, Political, Economic and Cultural Issues; Armitage, J., Roberts, J., Eds.; University of Northumbrian: Newcastle, UK, 1999; Available online: http://www.sabine-pfeiffer.de/files/downloads/1999_work_cybersoc_artikel.pdf (accessed on 30 January 2016).

27. Böhle, F.; Bolte, A.; Drexel, I.; Dunkel, W.; Pfeiffer, S.; Porschen, S. Umbrüche im Gesellschaftlichen Umgang mit Erfahrungswissen-Theoretische Konzepte, Empirische Befunde, Perspektiven der Forschung; ISF München: München, Germany, 2002. (In German)

28. Yin, R.K. Case Study Research: Design and Methods; Sage: London, UK, 2013.

29. Kagermann, H.; Wahlster, W.; Helbig, J. Recommendations for Implementing the Strategic Initiative INDUSTRIE 4.0. Final Report of the Industrie 4.0 Working Group; Acatech: Frankfurt/M., Germany, 2013; Available online: http://www.acatech.de/fileadmin/user_upload/Baumstruktur_nach_Website/Acatech/root/ de/Material_fuer_Sonderseiten/Industrie_4.0/Final_report_Industrie_4.0_accessible.pdf (accessed on 30 January 2016).

30. Glaser, B.G. Basics of grounded theory analysis: Emergence vs forcing; Sociology Press: Mill Valey, CA, USA, 1992.

31. Mayring, P. Qualitative Content Analysis. Forum: Qualitative Social Research, 2000, 1, Art. 2078. Available online: http:/ /www.qualitative-research.net/index.php/fqs/article/view/1089/2386 (accessed on 30 January 2016).

32. Kelle, U. Emergence vs. Forcing of Empirical Data? A Crucial Problem of "Grounded Theory" Reconsidered. Forum: Qual. Soc. Res. 2005, 6, Art. 2778. Available online: http://www.qualitative-research.net/index.php/ fqs/article/viewFile/467/1001 (accessed on 30 January 2016).

33. Pfeiffer, S. Montage und Erfahrung. In Warum Ganzheitliche Produktionssysteme Menschliches Arbeitsvermögen Brauchen; Hampp: München, Germany, 2007.

34. Noble, D.F. Progress without People. New Technology, Unemployment, and the Message of Resistance; Between the Lines: Toronto, ON, Canada, 1997.

35. Brynjolfson, E.; McAfee, A. The Second Machine Age: Work, Progress, and Prosperity in a Time of Brilliant Technologies; W. W. Norton \& Co.: New York, NY, USA, 2014.

36. Pistono, F. Robots Will Steal Your Job But That's Ok. How To Survive the Economic Collapse and be Happy; Pistono: Los Angeles, CA, USA, 2014.

37. Pupo, A. Cognitivity Everywhere: The Omnipresence of Intelligent Machines and the Possible Social Impacts. World Future Rev. 2014, 6, 114-119. [CrossRef]

38. Neumann, H. Eine große Chance für die Arbeit. Süddeutsche Zeitung, 6 October 2014. (In German)

39. WEF. The Future of Manufacturing: Driving Capabilities, Enabling Investment; World Economic Forum: Davos, Switzerland, 2015. 
40. Moniz, A.B. Intuitive Interaction Between Humans and Robots in Work Functions at Industrial Environments. In The Role of Social Robotics. In Social Robots from a Human Perspective; Vincent, J., Taipale, S., Sapio, B., Lugano, G., Fortunati, L., Eds.; Springer: Heidelberg, Germany, 2015; pp. 67-76.

41. Kaivo-oja, J.; Roth, S. The Technological Future of Work and Robotics; Inderscience: Genève, Switzerland, 2015.

42. IFR. World Robotics. Industrial Robots 2015-Executive Summary; International Federation for Robotics: New York, NY, USA, 2016.

43. Dekker, S.S.; Woods, D.D. MABA-MABA or abracadabra? Progress on Human-Automation Co-ordination. Cogn. Technol. Work 2002, 4, 240-244. [CrossRef]

44. Mukerji, C. Impossible Engineering: Technology and Territoriality on the Canal du Midi; Princeton University Press: Oxford, UK, 2009.

45. Baxter, G.; Rooksby, J.; Wang, Y.; Khajeh-Hosseini, A. The Ironies of Automation ... Still going strong at 30 ? In Proceedings of the 30th European Conference on Cognitive Ergonomics ECCE, Edinburgh, UK, 28-31 August 2012; pp. 65-71. Available online: http://johnrooksby.org/papers/ECCE2012_baxter_ironies.pdf (accessed on 30 January 2016).

(C) 2016 by the author; licensee MDPI, Basel, Switzerland. This article is an open access article distributed under the terms and conditions of the Creative Commons Attribution (CC-BY) license (http://creativecommons.org/licenses/by/4.0/). 